\title{
Article \\ Characterisation of Thunderstorms with Multiple Lightning Jumps
}

\author{
Tomeu Rigo ${ }^{*,+}+$ and Carme Farnell ${ }^{+}$(i)
}

check for

updates

Citation: Rigo, T.; Farnell, C.

Characterisation of Thunderstorms with Multiple Lightning Jumps. Atmosphere 2022, 13, 171. https:// doi.org/10.3390/atmos13020171

Academic Editor: Farhad Rachidi

Received: 17 December 2021

Accepted: 16 January 2022

Published: 21 January 2022

Publisher's Note: MDPI stays neutral with regard to jurisdictional claims in published maps and institutional affiliations.

Copyright: (c) 2022 by the authors. Licensee MDPI, Basel, Switzerland. This article is an open access article distributed under the terms and conditions of the Creative Commons Attribution (CC BY) license (https:// creativecommons.org/licenses/by/ $4.0 /)$.
Meteorological Service of Catalonia 1, C/Berlin, 38-46, CP 08029 Barcelona, Spain; carme.farnell@gencat.cat

* Correspondence: tomeu.rigo@gencat.cat

+ These authors contributed equally to this work.

\begin{abstract}
Several works have shown that lightning jumps are precursors of severe weather in deepconvective thunderstorms. Since 2017, the Meteorological Service of Catalonia has operationally run an algorithm that identifies lightning jumps (LJs) in real time. It has resulted in being an effective tool for nowcasting severe weather with a lead time between $15 \mathrm{~min}$ and $120 \mathrm{~min}$ in advance. This time can be of high value for managing emergencies caused by severe phenomena or heavy rains. The present research focused on the events' analysis in which more than one lightning jump occurred, searching for those elements that differentiate single warning cases. Thunderstorms producing LJs were divided into two main categories, depending on the number of jumps triggered during the life cycle. Besides, both classes were split into two main sub-types, based on the level of the LJ that occurred. Multiple LJ thunderstorms produce more Level 2-related to severe weather-jumps than Level 1-small hail or intense precipitation-while in the case of a single LJ, the opposite behaviour occurs. In general, multiple LJ thunderstorms with at least one Level 2 jump are the more intense and have a higher vertical development. Finally, lineal and well-organised thunderstorms are the more common modes in those intenser cases.
\end{abstract}

Keywords: lightning jump; severe weather; electrical activity; weather radar; multiple warnings

\section{Introduction}

Lightning jumps (LJs) are defined as a sudden increase of the total lightning (TL) activity in a thunderstorm [1-3]. This electrical activity arises commonly as a precursor of severe weather phenomena (tornadoes, straight-winds exceeding $25 \mathrm{~m} / \mathrm{s}$, or large hail over $2 \mathrm{~cm}$ in diameter) at the ground or short and very intense rain events [4-6]. An algorithm has shown good efficiency for nowcasting both types of phenomena (severe weather and intense precipitation) in convective or deep-convective events, with probabilities of detection of $80 \%$ and a false alarm ratio under the $20 \%$. However, at this time, the tool has not resulted in being efficient for discriminating the expected hail size [7]. In any case, analysing the time series of LJ can provide a new way of understanding the processes associated with extreme precipitation, including large hail phenomena.

A crucial point in the favourable functioning of the algorithms detecting LJs is the capability of detection of the Lightning Location System (LLS) network, especially of the intra-cloud (IC) flashes [8-10]. The most common way of identifying LJs [1,2,8,11] is detecting an increase of the TL activity exceeding $2 \sigma$ (this being double the standard deviation of the rate in a previous period of between $10 \mathrm{~min}$ and $15 \mathrm{~min}$ ). Although this algorithm was developed for the terrain LLS, it has recently been applied to satellite imagery, taking advantage of the spatial coverage and the capability of detecting a high percentage of the ICs occurring in thunderstorms $[12,13]$. However, the results have not been as good as expected, probably because of the worse time and spatial resolutions, with respect to the terrestrial systems.

Some researches have focused on the physics of those thunderstorms producing LJs, combining electrical data with radar information $[3,7,9,11,14-17]$. The previous works 
considered different radar variables and searched for some key signatures. In this way, Reference [11] detected a good correlation between thunderstorms producing LJs and the vertical integrated liquid (VIL) radar parameter, in concordance with the results of [15], who used the graupel mass estimation at high levels. Reference [9] also observed the same behaviour with the VIL, but the VIL density outperformed in most cases. Reference [3,7] detected that the size of the thunderstorm has a significant role in the triggering of the warning because it affects the number of lightning flashes. Similar results were found by [16,17], who considered the regions exceeding $46 \mathrm{dBZ}$ and $55 \mathrm{dBZ}$ (in the first case) and $40 \mathrm{dBZ}$ (n the second case) in hail- and non-hail-producing thunderstorms. Finally, Reference [14] detected a large number of false alarms in non-severe thunderstorms using the algorithm of [3] and a lightning mapping array (LMA) system (more than 50\%).

The studies of $[11,15]$ (among others) showed that some thunderstorms produce multiple LJs, which can be different in the sense of the type of total lightning increase (more or less abrupt) and the number of flashes registered in the thunderstorm. However, the number of analysed cases was in all cases relatively low. In 2017, the Meteorological Service of Catalonia put in operation the algorithm of [1], with the preliminary work of testing and tuning the parameters according to the Catalan Lightning Location System (LLS), the necessities of the Surveillance and Forecasting Team, and the characteristics of the terrain and the meteorology of the region. Then, a large set of cases has become available for the area of interest since 2006 [4]. This is the basis of the current research, presented in the following sections.

The present research aimed to identify principal signatures in radar data detected mainly in thunderstorms with multi-LJ warnings in front of those single-warning cases (MLJst and SLJst, respectively). Besides, the analysis included other time and spatial patterns, such as the relationship with the Mediterranean Sea and the topography.

\section{Materials and Methods}

\subsection{Area of Study and the Data Used}

Two main data sources were used in the analysis of the MLJst. The first was lightning data, used for the triggering of the LJs themselves and also for the determination of the area considered associated with the same storm. The second type of data was weather radar information. In this case, these were used for identifying the convective cells included in the LJ-producing storm. Besides, this allowed determining some parameters that could discriminate between the SLJst and MLJst. Figure 1 shows the location of both networks of data sources (radar and lightning detectors) in the region of study, Catalonia. This region is located in the NW of the Mediterranean Basin. The principal mountain ranges reach between $2000 \mathrm{~m}$ and $3000 \mathrm{~m}$ and are distributed from west to east. Other minor mountainous structures are between $500 \mathrm{~m}$ and $1500 \mathrm{~m}$, running quasi-parallel to the coastline.

\subsubsection{Lightning Data}

The LLS (known as XDDE, from the Catalan "Network of Electrical Discharges Detection") of the Meteorological Service of Catalonia (SMC) is composed of four low-frequency (LF) and very-high-frequency (VHF) sensors (each sensor has two antennas, detecting both frequencies). This configuration allows a good detection of both cloud-to-ground (CG) and intra-cloud (IC) flashes (the detection efficiency moves between $80 \%$ and $95 \%$, and $65 \%$ and $85 \%$, respectively, according to the manufacturer's software and the experimental campaigns cited in [1]). IC lightning (Figure 2) comprises those cloud discharges that occur totally inside a single convective cell and are the most common of all the forms of lightning, while CG lightning comprises those that overpass the hole between the cloud charge and the Earth' surface [18-20]. Positive CGs usually present a unique return stroke after the stepped leader, in front of the multiple-return strokes observed in negative CGs. The LLS of the SMC can detect multiple return strokes in CGs. Besides, it can register many sources in ICs. In this sense, flashes are integrated into a database considering multiple locations 
(defined here as Level 1) or a unique position (Level 2). The ability to detect more or less IC sources or return strokes is dependant on the distance of the thunderstorm to the LLS sensors. Then, one thunderstorm occurring in the region inside the polygon closed by the position of the sensors will have a higher rate between the number of sources at the two levels. In this sense, the median value of the rate for the year 2021 was 5.83 (for 103,145 cases of at least one minute of lightning activity over Catalonia).

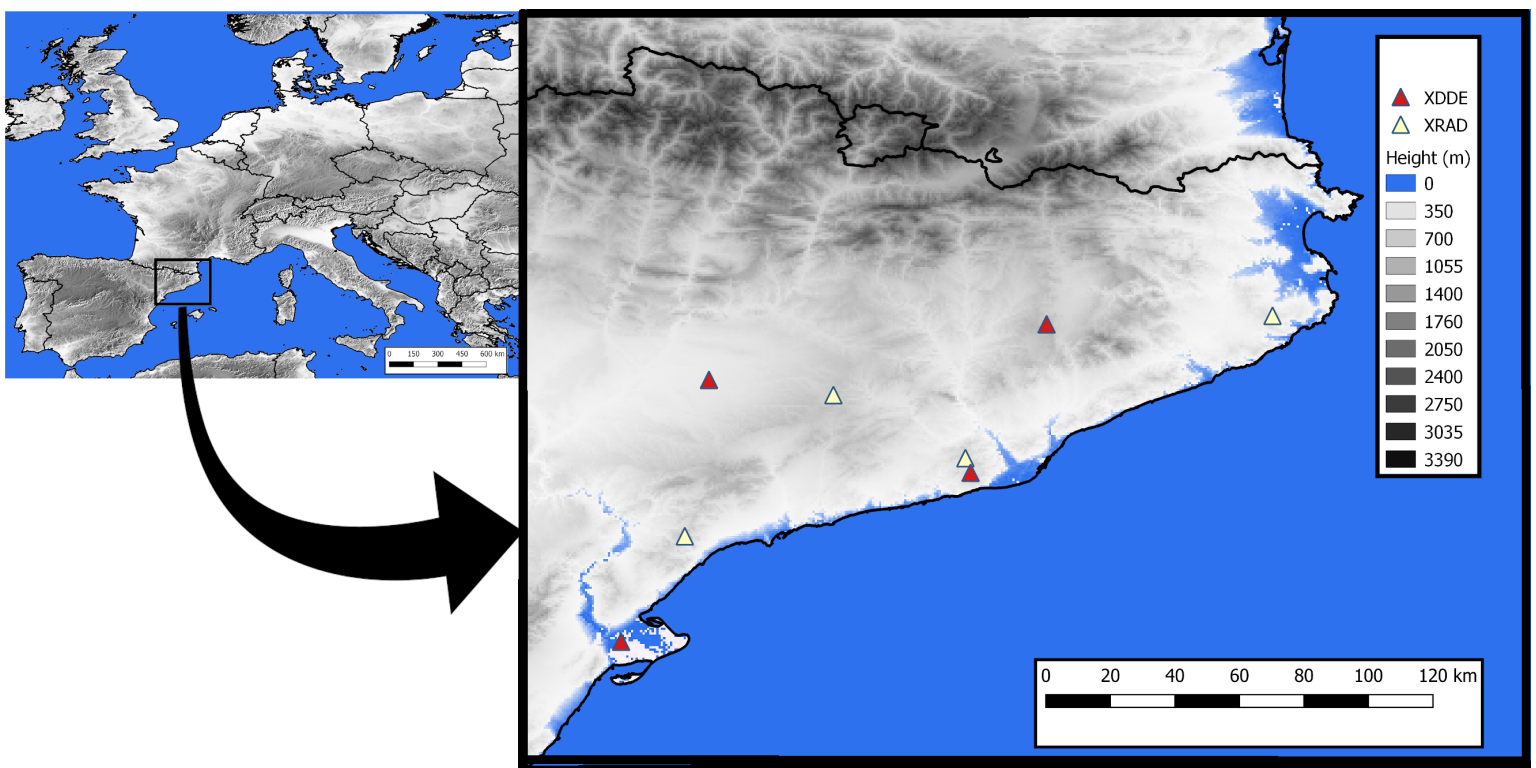

Figure 1. Geographic location of the area of study. (Left) European map with the region of interest marked with a black rectangle. (Right) Zoom of the region of interest showing the location of the elements of the LLS (red triangles) and of the XRAD (yellow triangles).

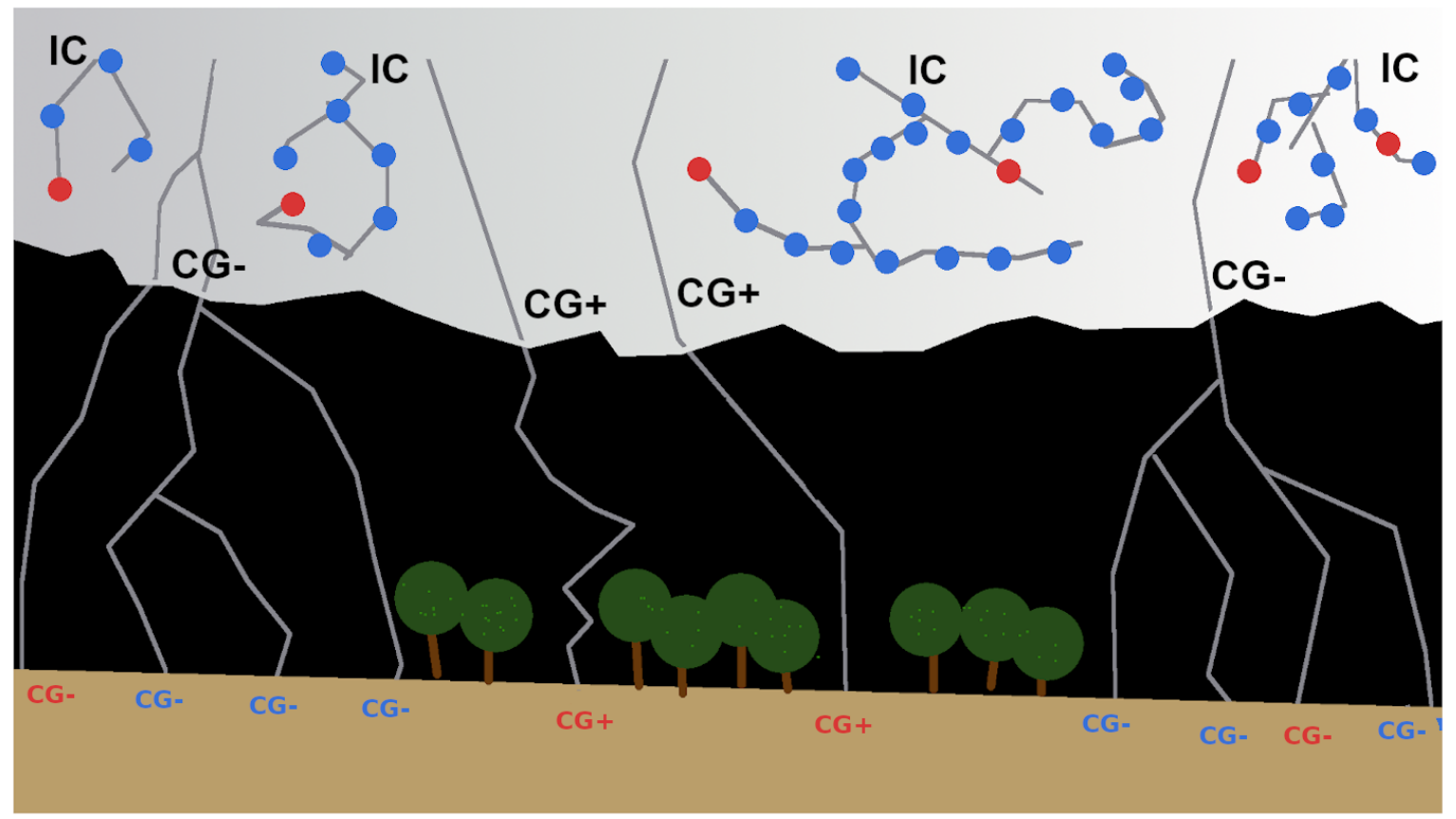

Figure 2. Scheme of the different types of lightning (IC: intra-cloud, CG+: positive cloud-to-ground, CG-: negative cloud-to-ground) in a thunderstorm and the sources (blue ones correspond to Level 1-multiple TL sources-and red ones to Level 2-single flash sources) detected for each one (based on [20]). 


\subsubsection{Radar Data}

The SMC manages a radar network (XRAD) composed of 4 C-Band single-polarisations, with two operational ranges: the longest one, for surveillance tasks and reaching $250 \mathrm{~km}$ from each radar, is generated using only a unique elevation at $0.6 \mathrm{deg}$. The volumetric range is only $130 \mathrm{~km}$ from the radar. However, it consists of 13 elevation angles (from 0.6-30 deg), allowing generating quantitative precipitation estimation and other products with a good performance over the Catalan territory and the neighbouring areas. Radar volumes are generated every $6 \mathrm{~min}$, and the composition of all the elements is performed on a computer in the central offices, considering maximum reflectivity values.

\subsection{Methodology}

This section presents the different steps in the research, starting from the thunderstorm identification to the identification of thunderstorms with lightning jumps.

\subsubsection{Identification and Tracking of Thunderstorms Using Lightning Data: Lightning Jumps}

Figure 3 shows schematically the way a thunderstorm is identified using lightning data. Red dots correspond to the main source of each IC and CG lightning, while the blue ones indicate the position of secondary sources of the flashes of a thunderstorm. All those sources are integrated in $2 \times 2 \mathrm{~km}^{2}$ pixels of a matrix [1], to indicate regions with or without lightning activity. Each minute, two matrices are generated (with-red and blue dots—and without-only red dots-multiplicity), for a region coinciding with the XRAD coverage. All those pixels with at least two sources and with also other pixels in the surroundings verifying the same condition are considered as candidate elements of the matrix. These candidate elements are merged into unique structures that correspond to the thunderstorm structure. Then, all thunderstorms are characterised every minute considering the location of the centroid $\left(\mathrm{x}_{\mathrm{c}}, \mathrm{y}_{\mathrm{c}}\right)$, the time, the total area (or number of pixels), and the number of sources. The most relevant point of the differences between the structures identified using single or multiple sources per lightning is that in the second case, it is easier to perform the identification and tracking in time of the thunderstorm (because the footprint is clearer in the matrix), but a thunderstorm with a clear signal in time in the case of single sources reveals a major relationship with a strong updraught (which is the main cause of the increase of the lightning activity in a thunderstorm). This point will be explained more in depth in the next section, when these tracking results are compared with the radar ones.
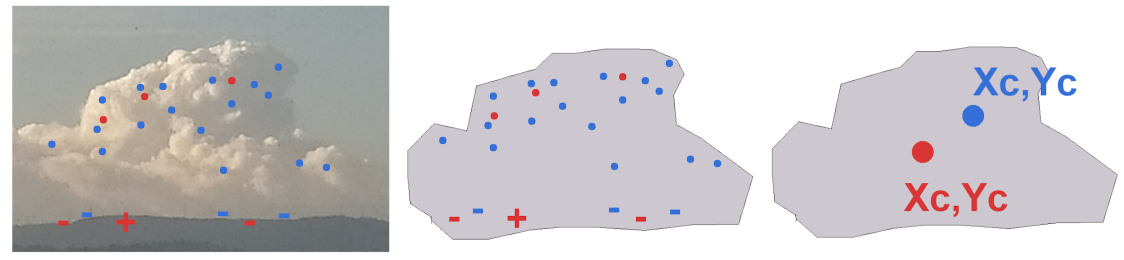

Figure 3. Idealised identification of different types of sources in a thunderstorm and its idealistic transformation into two centroids, which characterise the storm at a certain time.

The tracking of a thunderstorm is performed each minute considering the total lightning (in both single- and multiple-source ways). The TL is the magnitude used for estimating the LJ's occurrence, considering that at a certain time, the increase of its value should exceed the $2^{*} \sigma$ threshold, for the previous $14 \mathrm{~min}$. Figure 4 shows an example of the tracking and the TL evolution of the same thunderstorm, from the single- and multiple-source approaches. It can be observed how in both cases, an LJ occurred, but the time of triggering was different. Besides, the path and the TL evolution were different, as happened in practically all thunderstorms analysed. Finally, it is worth saying that the 
order of magnitude of the TL in the multiple sources is one degree larger than in the case of the single source.

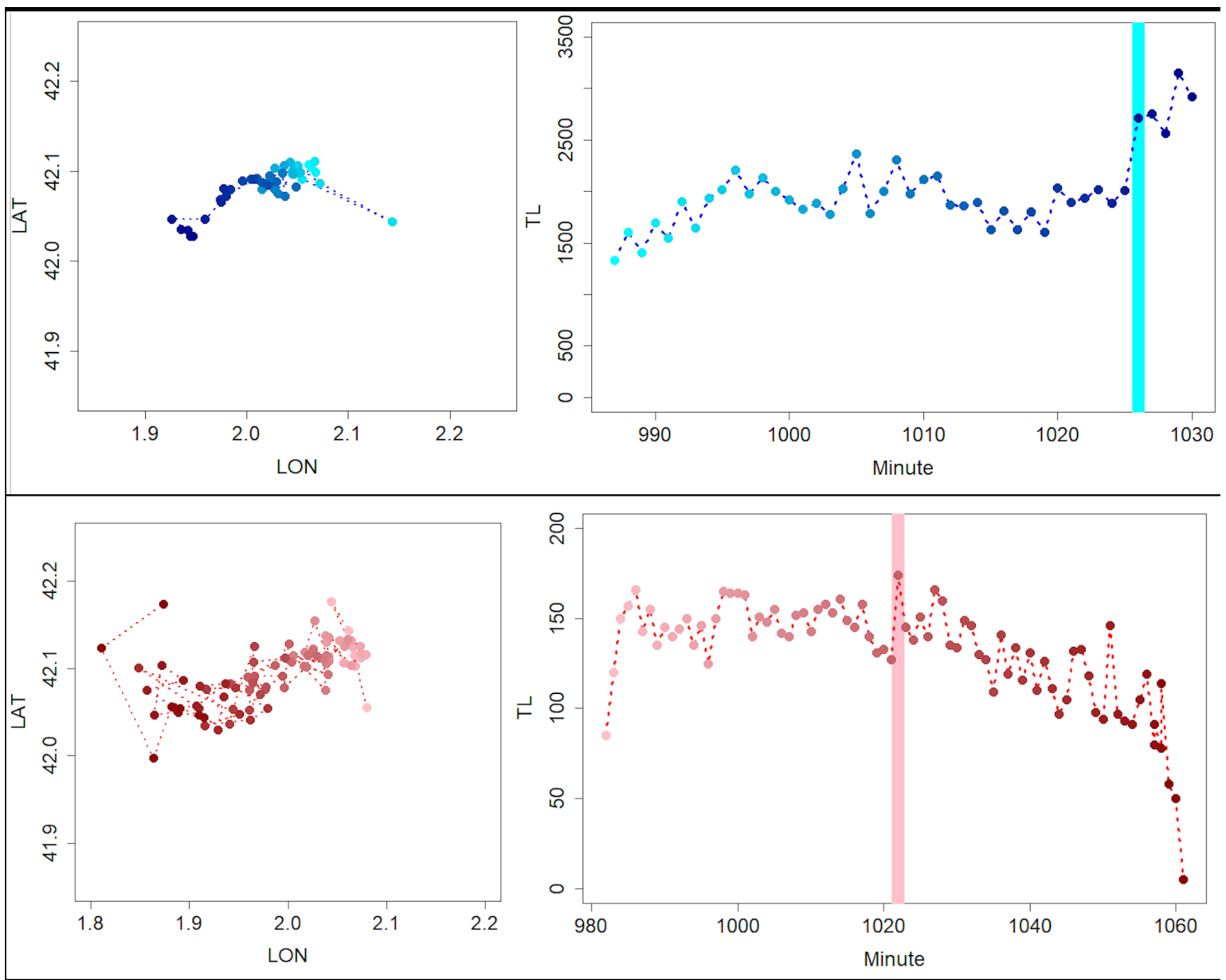

Figure 4. Examples of the partial life cycles of a thunderstorm for the Level 1 (multiple sources) centroids and lightning jump warning (above) and the same for single-TL sources detected, or Level 2 (below). Left panels correspond to the trajectories and right ones to the total lightning time evolution. The vertical shaded lines indicated the time the lightning jumps occurred. Event of 6 September 2021.

\subsubsection{Identification and Tracking of Thunderstorms Using Radar Data}

The identification, tracking, and nowcasting of thunderstorms working at the SMC were presented in [21]. This consists of the analysis of the 10-level constant altitude plan position indicator (CAPPI) generated for the composition of the XRAD every $6 \mathrm{~min}$. The technique is a multi-threshold reflectivity (35-65 dBZ, with gaps of $5 \mathrm{dBZ}$ ) searching for those regions exceeding $24 \mathrm{~km}^{2}$ for the largest reflectivity threshold, for each one of the 10 CAPPI. Then, the areas are connected vertically, obtaining a 3D volume associated with every thunderstorm. Several parameters characterise the cell: the 3D centroid, the heights of the top and the base, the maximum and mean reflectivity, the volume, and the VIL, among others. This information allows performing an accurate tracking of most of the thunderstorms. Figure 5 shows the tracking and the part of the life cycle of a severe thunderstorm that occurred on 6 September 2021, which produced a hailfall with stones of a diameter over the $6 \mathrm{~cm}$.

The previous figure illustrates some important questions to have in mind at the time of using the LJ tool operationally. Firstly, one of the main advantages is the time resolution (one minute) and the short delay (also one minute), in front of the weather radar volumetric composite and its final tracking product (six minutes and three minutes of resolution and delay, respectively). However, the capability to provide an accurate location decreases 
when we consider the multi-source lightning data, and especially for the case of the single source. Besides, because of the use of different restrictions in the number of TLs and the area, the first and last stages of the thunderstorm's life cycle are detected. In any case, the good results (with a CSI [22] skill score over 70\%) of the LJ in the real-time operational performance of the tool indicate that these issues are important, but not a constrain in most of the events. In any case, the good results (with a CSI [22] skill score over 70\%) of the LJ in the real-time operational performance of the tool indicate that these issues are important, but not a constraint in most of the events.
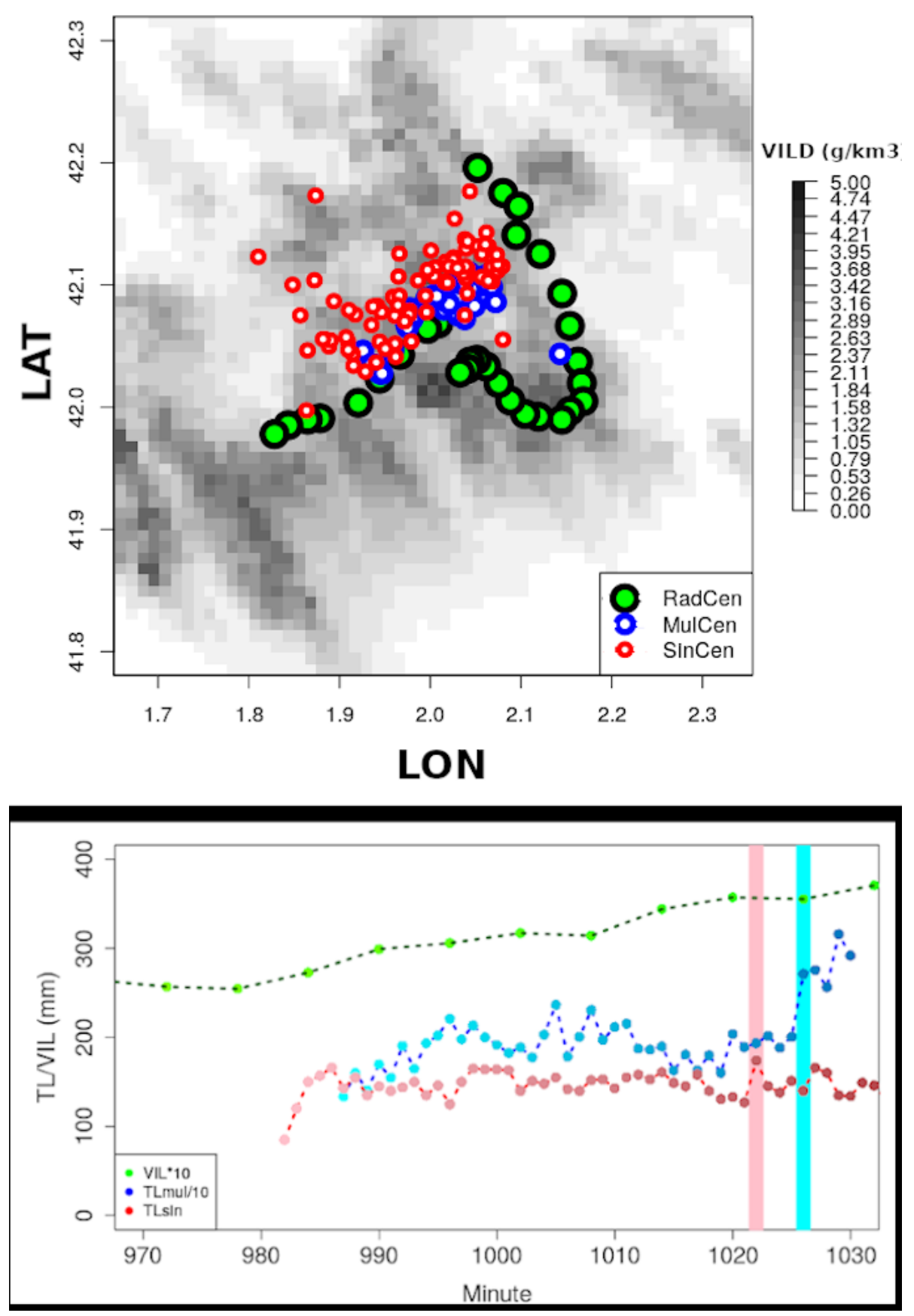

Figure 5. (Above) Partial tracking of the same thunderstorm presented in Figure 4, but considering the radar information (green points), the single-TL information (red dots), and the multiple-TL data (blue points). (Below) Partial life cycle of the same thunderstorm, showing the VIL evolution (6 min time resolution) and the TL with single- (red) and multiple- (blue) lightning sources. The vertical lines indicate the time of occurrence of the two LJs. 


\subsubsection{Characterisation of Thunderstorms with Lightning Jumps}

The main point of the research consists of the identification and characterisation of those thunderstorms producing LJs. To do this, the data bases of LJs, single-TL sources, and radar convective cells were analysed, considering the following steps (Figure 6):

- Identify each LJ, and search for other ones occurring at a distance of less than $50 \mathrm{~km}$ and no later than $2 \mathrm{~h}$ (the thresholds are based on the operational campaigns of 2018 to 2021; none of the thunderstorms produced two correlative LJs with differences in time and space exceeding those values);

- Confirm that the two LJs correspond to the same thunderstorm; the map of the TL density of single sources has a plot confirming or not that there is spatial continuity in the electrical activity between both LJs, as shown in Figure 6;

- $\quad$ The last step includes all the cells during the period when the thunderstorm occurred in the region of electrical activity.
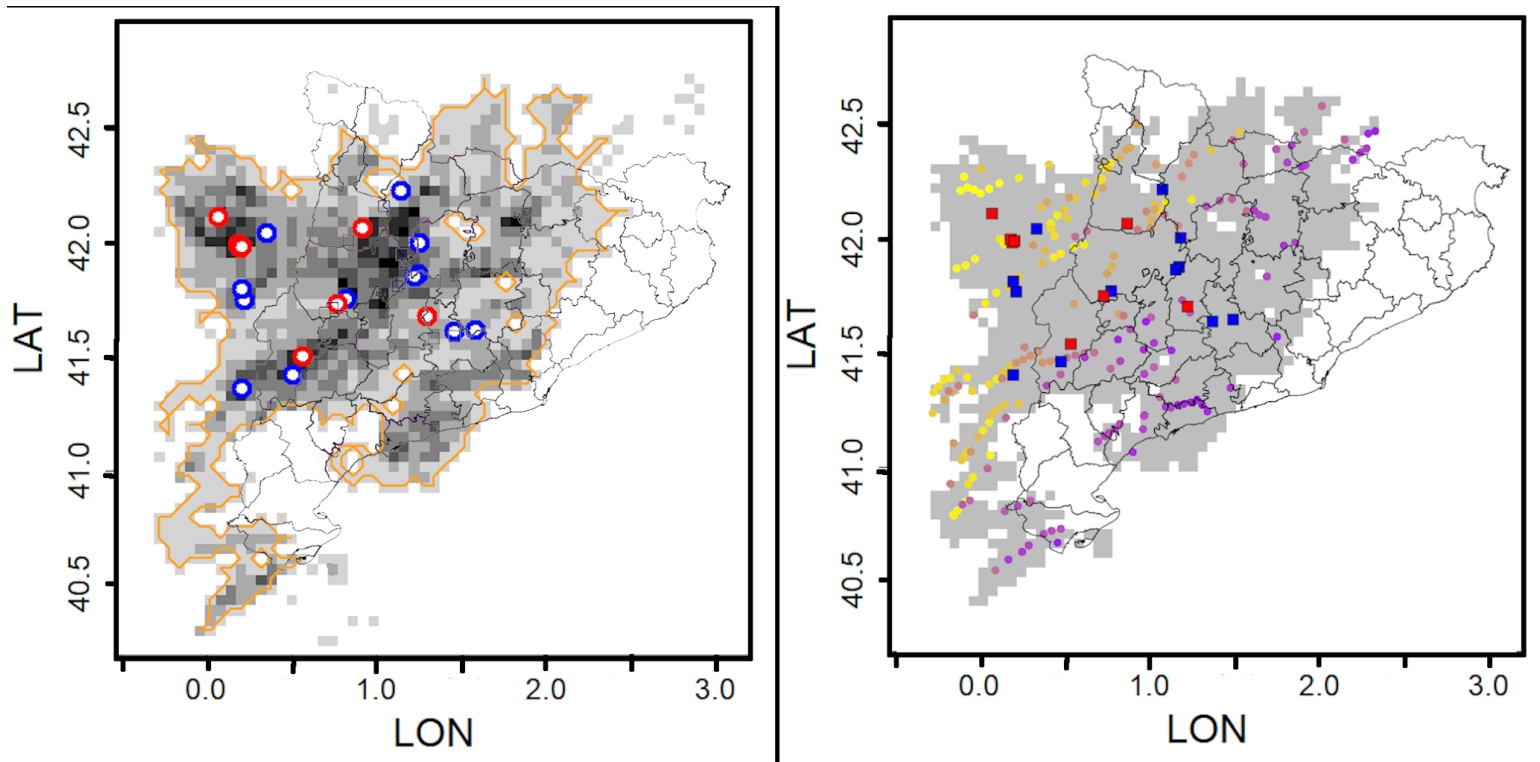

Figure 6. (Left) Total lightning area (shaded grey region) associated with multiple-lightning jump warnings (blue dots correspond to multiple-lightning sources and red ones to single sources). The orange line encloses the area associated with the warnings. Case of 10 October 2013. (Right) The same as the left panel (LJs marked with blue and red squares), but including the centroids of the thunderstorms identified based on the volumetric radar product (circle dots).

The thunderstorms were characterised by different types of variables: the initial and ending times (with the format: year, month, day, hour, and minute), the area of TL activity, the duration, the number of LJs, which corresponded to single- (Level 2) or multi- (Level 1) source flashes, the number of radar cells, and the maxima and mean reflectivity, and the echo top. From this information, we tried to answer the following questions:

- Which is the period of greater occurrence of LJ thunderstorms? Which is the part of the day with a higher probability?

- Is SLJst or MLJst more common?

- Which are the radar parameters that act to discriminate between single- and multipleLJ thunderstorms?

- Which are the usual degrees of convective organisation associated with multiple LJs?

\section{Results}

The analysis of the dataset of LJs of both levels, 1 (multi-source TL) and 2 (singlesource TL), included a total of 8906 LJs, for the period 1 January 2006 to 30 September 2021. This value corresponds to $982 \mathrm{~d}$ with, at least, one LJ, of the total of $5752 \mathrm{~d}$ of the 
full period. This implies that in a $17.1 \%$ of the days of the period, at least one LJ occurred. Having in mind that the convective period in the region of study goes from April to October, the period where the probability of the major occurrence of LJs reduces to $3393 \mathrm{~d}$ and the percentage of days with LJs (considering that there were $937 \mathrm{~d}$ with LJs during these months) increased to $27.6 \%$. The next sections present the analysis of the different characteristics of the thunderstorms producing single- and multiple-LJs during this period.

\subsection{Short Climatology of Thunderstorms Producing LJs in Catalonia}

From the eight-thousand, nine-hundred and six LJs and considering the previous criteria that two LJs correspond to the same thunderstorm if they occurred at a distance less than $50 \mathrm{~km}$, a time gap under $120 \mathrm{~min}$, and a continuity in the single-source TL field, we found that they could be grouped into two-thousand, four-hundred and seven thunderstorms, from which eight-hundred were were SLJsts and one-thousand six-hundred and seven were MLJsts (that is, $59.4 \%$ of the thunderstorms producing LJs were MLJsts).

The monthly distributions of SLJsts and MLJsts (Figure 7) showed a similar shape, with a normal curve with a maximum probability for the months June and July. However, there were significant differences, which could be relevant in terms of operational purposes. The first one is that the months August and September present similar probabilities of occurrence (only a bit lower) than June and July in the cases of SLJsts, while the differences are more significant in the case of the MLJsts. Then, the probability of having an MLJst decreases while the SLJst occurrence increases as we move far from June and July. In this sense, the cases with MLJsts for the months December, January, February, and March are practically null, and only SLJsts are usual. Finally, November is the unique month out of the convective period (April to October) where the probability of MLJsts is more relevant than in the case of SLJsts.

\section{Monthly distribution}

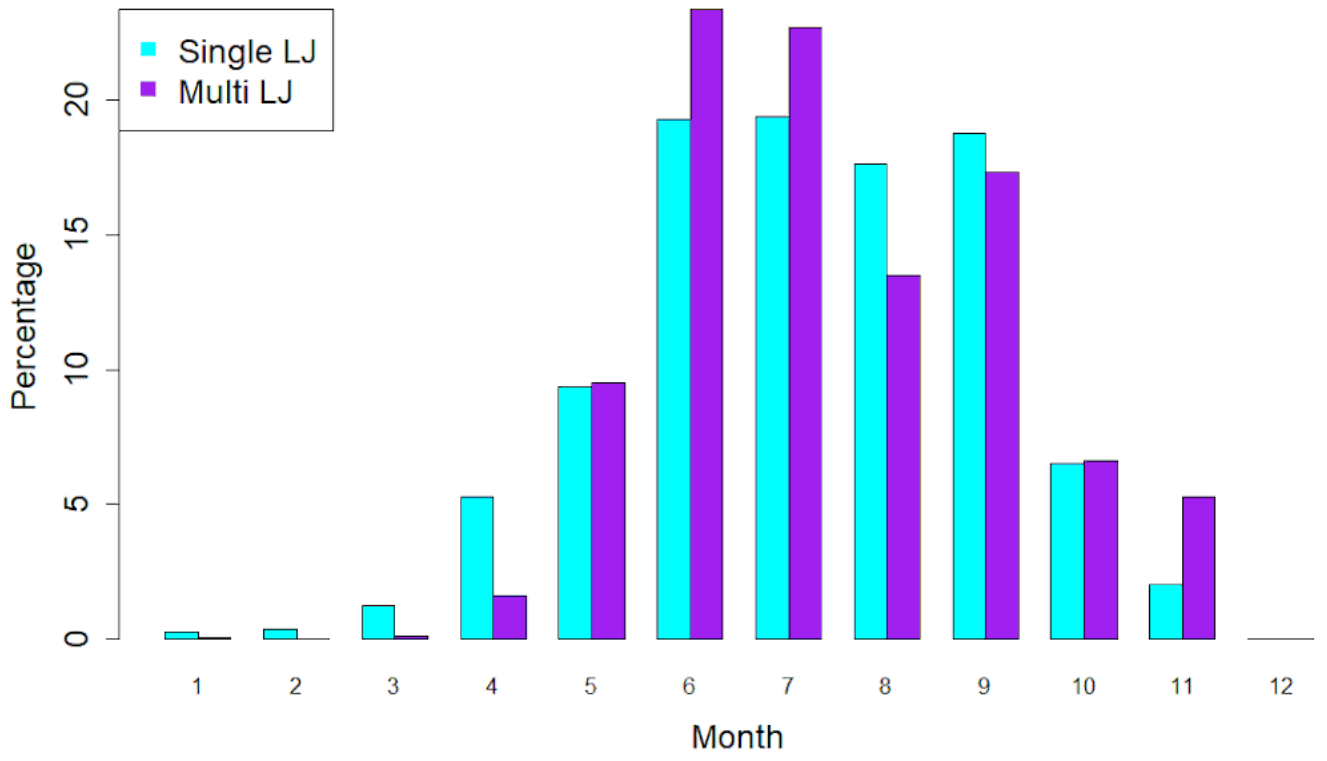

Figure 7. Monthly distributions (in percentage) of the SLJsts (cyan) and MLJsts (purple).

The hourly distributions (Figure 8) also presented the same pattern, with the maximum probability of occurrence between 12 UTC and 18 UTC (coinciding with the diurnal cycle of the convection). However, the peak of the SLJsts was sharper because their duration was shorter and more concentrated in less hours. On the other hand, the MLJsts can stand for longer periods, and then, LJs can also occur out of the maximum period. 


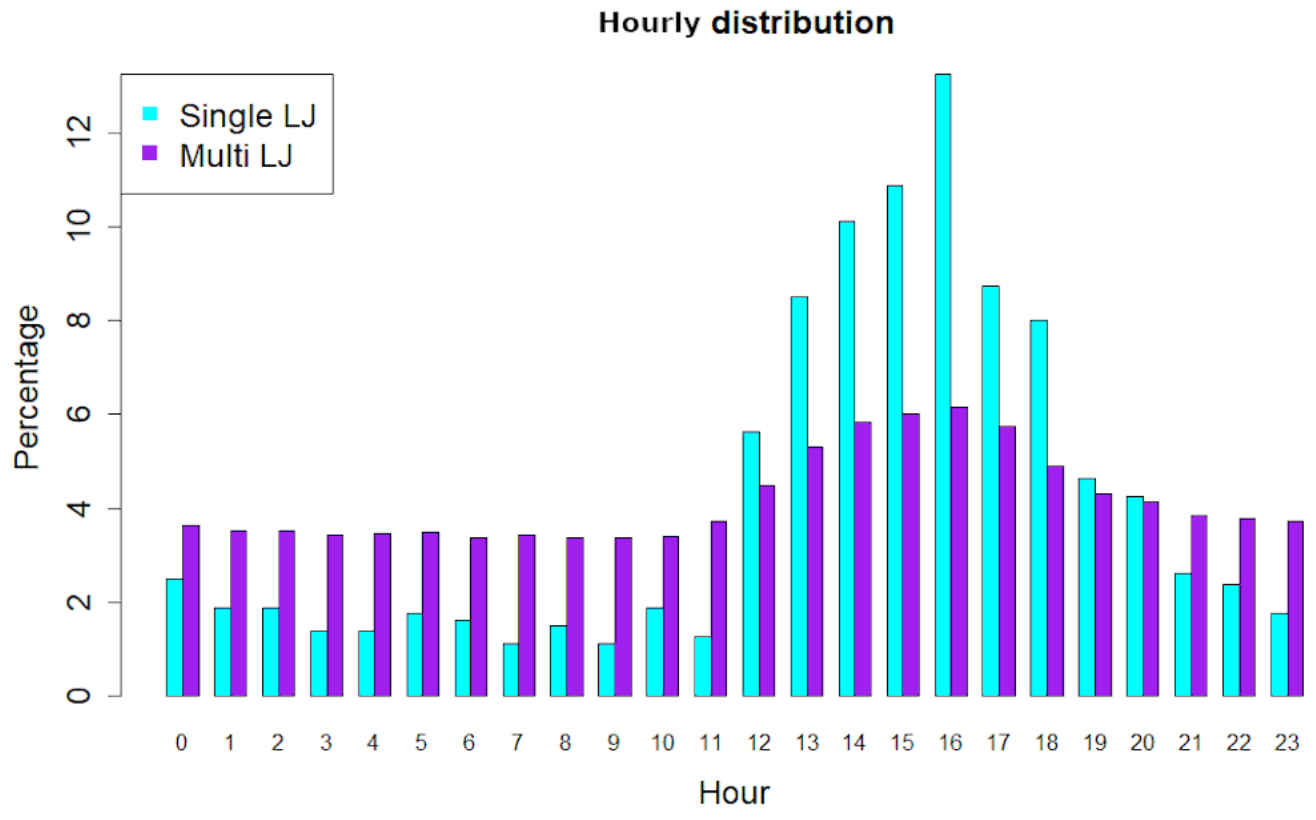

Figure 8. Hourly distributions (in percentage) of the SLJsts (cyan) and MLJsts (purple).

Considering the two levels of the LJs, the first associated with the detection of multiple sources of flashes (occurring in thunderstorms producing small hail, moderate wind gusts, or intense rainfalls) and the second linked to the single sources of the lightning in severe thunderstorms (the ones producing tornadoes, large hail, or strong wind gusts), Figure 9 presents which is the highest level of an LJ in SLJsts and MLJsts, respectively. In the case of MLJsts, a value of two does not mean that jumps of this level only have occurred. MLJsts usually produce both levels of LJs. In any case, SLJsts are more prone to give Level 1 jumps, while the contrary occurs in MLJsts. In this way, deeper convective thunderstorms will produce more than one LJ and at least one of Level 2 also.

\section{Level distribution}

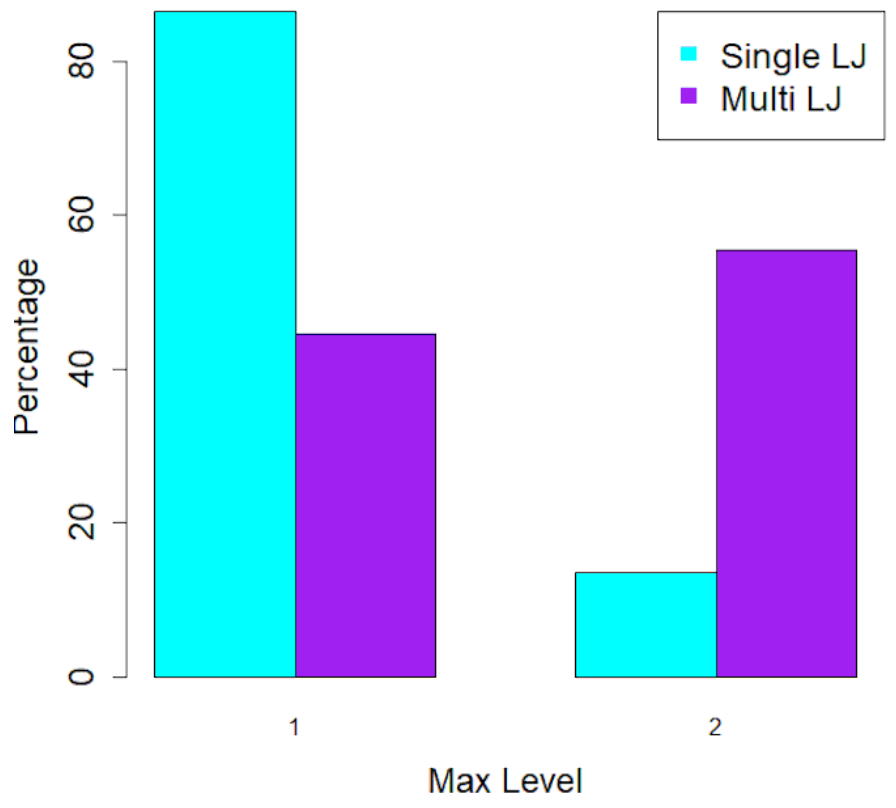

Figure 9. Maximum level distributions (in percentage) of the SLJsts (cyan) and MLJsts (purple). 
It is interesting to indicate that $44.6 \%$ (716) of MLJsts only produced Level 1 jumps. Of these MLJsts without Level 2 jumps, a 78.9\% (562) triggered three jumps as the maximum. Only $1 \%$ (eleven) of MLJsts with only Level 1 jumps produced nine or more LJ. We did not find any relevant feature of those cases regarding the normal distributions shown in the previous figures. On the other hand, in the case of the ninety three MLJsts that produced five or more jumps, the pattern was very relevant. There were $86 \%(80)$ of cases that occurred between July and September, and 40.1\% (38) of the thunderstorms developed between 13 UTC and 15 UTC. Then, diurnal and summer deep convection play a principal role in the occurrence of MLJsts with several jumps of Level 2.

To end this point, Table 1 presents the number (and the percentage) of thunderstorms of the different categories: single-LJ, 2 to 4 LJs, 5 to 9 LJs, 10 to 14 LJs, and more than 14 LJs. In all cases, the number of thunderstorms with Level 1 LJs was notably higher than of Level 2. Besides, all those thunderstorms with five or more LJ had, at least, one Level 1 jump. In the same way, the presence of Level 2 LJs in thunderstorms increased from the same value (this is, cases with five or more LJ).

Table 1. Number of thunderstorms (in parenthesis in the first row) with a single-LJ, between 2 and 4 LJs, 5 to 9 LJs, 10 to 14 LJs, and more than 14 LJs. Each category has two columns, with the number (and the percentage with respect to the total Ls of the selected category) of thunderstorms with at least one LJ of Level 1 (left) and Level 2 (right). Note that, except in the single-LJ case, the numbers are not complementaries.

\begin{tabular}{ccccccccccc}
\hline Number LJ & \multicolumn{2}{c}{$\mathbf{1}(\mathbf{8 0 0 )}$} & \multicolumn{2}{c}{$\mathbf{2 - 4}(\mathbf{1 0 1 3 )}$} & \multicolumn{2}{c}{$\mathbf{- 9}(\mathbf{4 1 6 )}$} & \multicolumn{1}{c}{$\mathbf{1 0 - 1 4} \mathbf{( 1 3 0 )}$} & \multicolumn{2}{c}{$>\mathbf{1 4}(\mathbf{4 8 )}$} \\
\hline LJ Level & 1 & 2 & 1 & 2 & 1 & 2 & 1 & 2 & 1 & 2 \\
\hline N cases & 691 & 109 & 967 & 384 & 416 & 338 & 130 & 122 & 48 & 47 \\
\hline$\%$ & 86.4 & 13.6 & 95.4 & 37.9 & 100 & 81.3 & 100 & 93.8 & 100 & 97.9 \\
\hline
\end{tabular}

\subsection{Radar Parameters Associated with Thunderstorms Producing LJS}

The analysis of the radar data in cases of thunderstorms producing LJs was performed using the information of the algorithm of identification, characterisation, tracking, and nowcasting of convective cells of the Meteorological Service of Catalonia [21]. This consisted of determining the behaviour of some signatures such as the number of convective cells and the reflectivity and the height of those cells. The thunderstorms were classified as: (1) with a single Level 1 jump (SLJst1), (2) with a single Level 2 jump (SLJst2), (3) with multiple jumps all of Level 1 (none of Level 2) (MLJst1), and (4) with multiple jumps and at least one of Level 2 (MLJst2). Figure 10 reveals how the MLJst2 category of thunderstorms presented the largest number of cells on average (with a mean value of five), probably because of the high degree of organisation of the convection and the largest duration. On the other hand, thunderstorms with MLJst1 had the lowest number of cells, with a mean value of two, a bit lower that the class of thunderstorms with SLJst2.

To discriminate the different categories of thunderstorms, we observed that the maximum values of reflectivity or echo top (for the $35 \mathrm{dBZ}$ reflectivity threshold, in this case) did not work properly. Most thunderstorms producing any class of LJ reached high values of both parameters, at least for a short period. However, from our experience and from the analysis of many of the thunderstorms of the dataset, it was possible to identify that the discriminating signatures were more related to the duration of the exceedance of certain thresholds. Because of this, we analysed the reflectivity at the surface and for the whole cell volume, as well as the echo top. In the first case, we considered two different thresholds: $40 \mathrm{dBZ}$ and $45 \mathrm{dBZ}$. Figure 11 presents how, in the first case, all thunderstorm categories exceeded the threshold for a more or less long period of the life cycle. However, MLJsts showed a higher duration of the exceedance, while SLJsts had a more brief period with intense reflectivity at the surface. However, if we move to the highest threshold, only MLJst2 had periods where $45 \mathrm{dBZ}$ were exceeded. Then, this type of thunderstorm has the highest and more intense exceedance periods of high reflectivity values. 


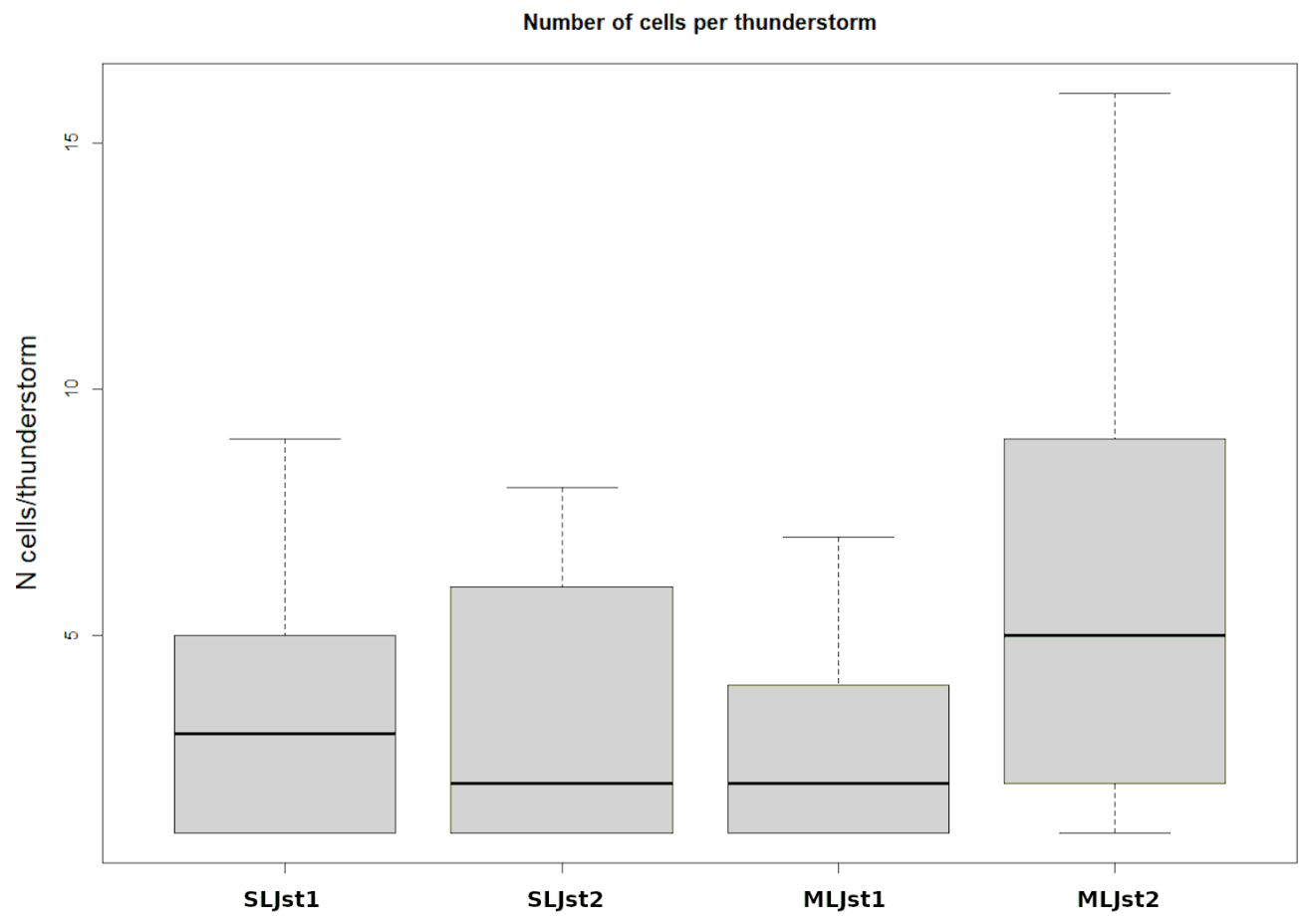

Figure 10. Boxplot of the number of convective cells identified in LJ thunderstorms. From left to right: SLJst1, SLJst2, MLJst1, and MLJst2.
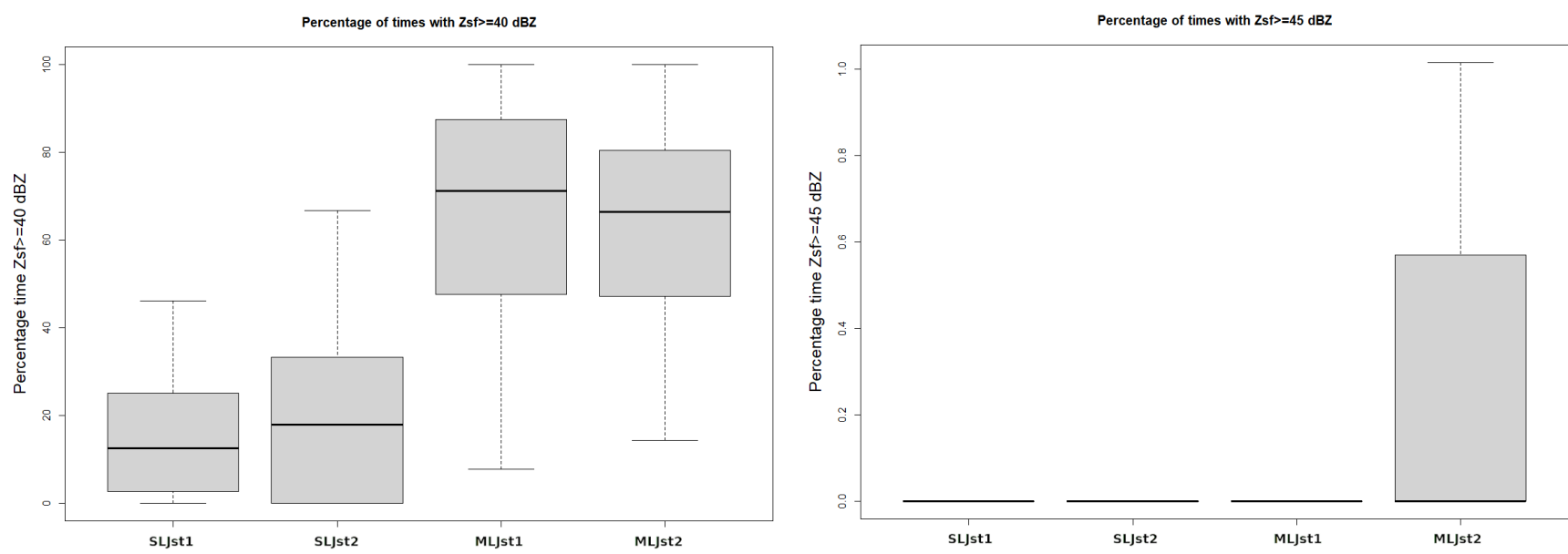

Figure 11. Same as Figure 10, but for the number of times that surface reflectivity exceeded a certain threshold: (left) $40 \mathrm{dBZ}$; (right) $45 \mathrm{dBZ}$.

In a similar way, but for the maximum reflectivity of the full cell volumes (Figure 12), the SLJsts usually had a shorter duration of exceedance of $45 \mathrm{dBZ}$ than MLJst. Besides, SLJsts rarely exceeded during their life cycle $55 \mathrm{dBZ}$, contrary to MLJst. Finally, it is important to remark that this exceedance was more common in MLJst2.

Finally, the echo top $35 \mathrm{dBZ}$ (Figure 13) presented again a similar behaviour as the reflectivities, for both thresholds of height exceedance $(6 \mathrm{~km}$ and $8 \mathrm{~km})$. SLJsts exceeded for a shorter time period both thresholds, in comparison to MLJsts. Besides, the values were larger in those MLJst2 cases. 

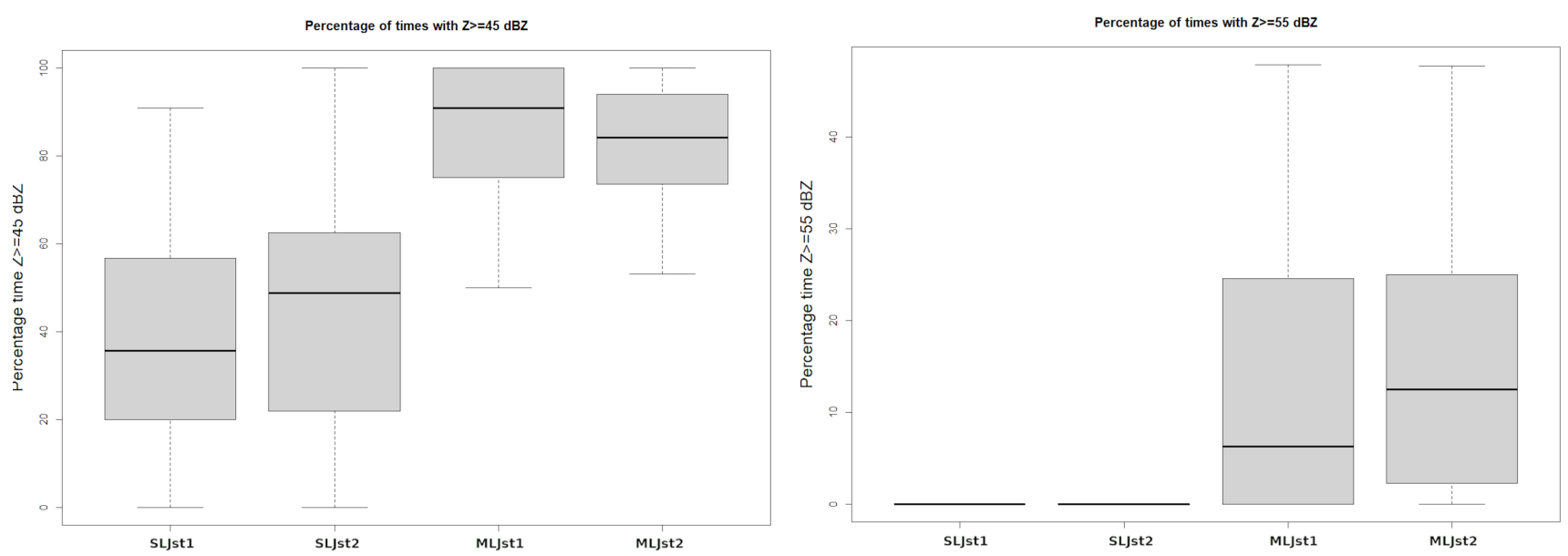

Figure 12. Same as Figure 10, but for the number of times that maximum reflectivity exceeded a certain threshold: (left) $45 \mathrm{dBZ}$; (right) $55 \mathrm{dBZ}$.
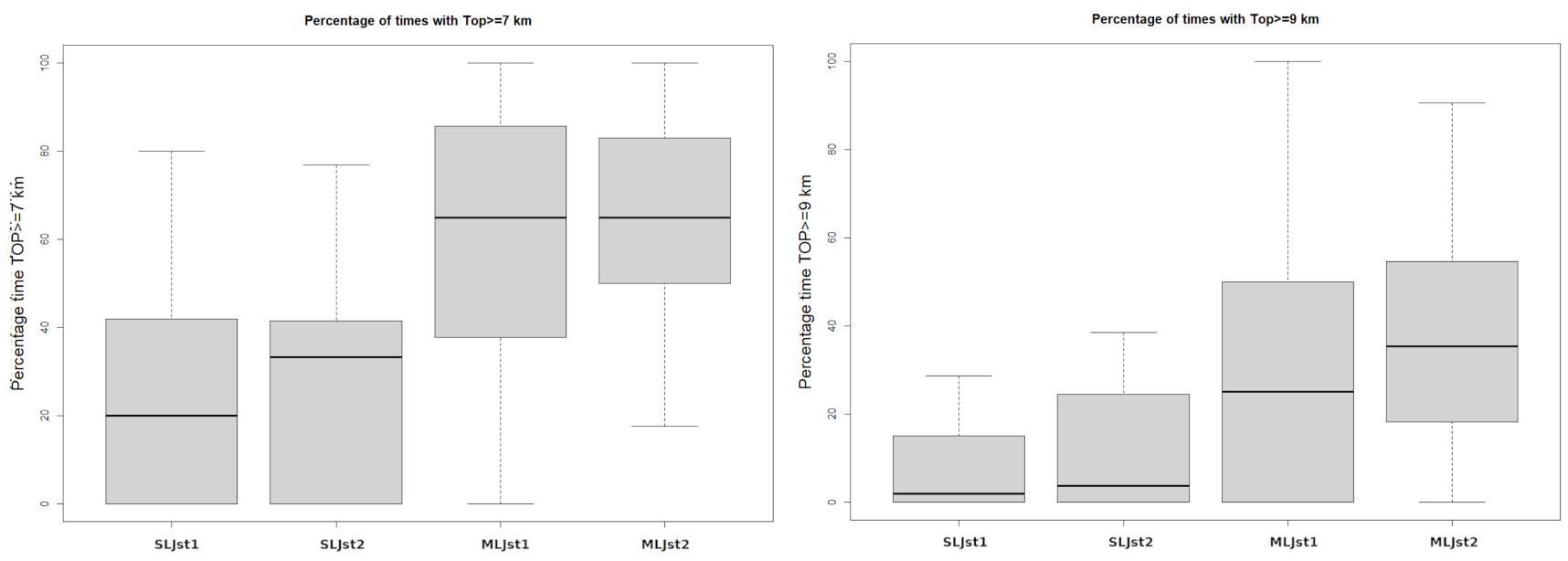

Figure 13. Same as Figure 10, but for the number of times that echo top $35 \mathrm{dBZ}$ exceeded a certain height threshold: (left) $6 \mathrm{~km}$; (right) $8 \mathrm{~km}$.

\subsection{Degree of Convection in Thunderstorms Producing LJs}

The set of LJ-producing thunderstorms were classified according to the scheme shown in Figure 14. The classification was performed by combining the automatic generation of the maps, as presented in Figure 7, and the visual analysis of these maps. It is worth noting some considerations regarding the classification. The first one regards the question of the subjectivity of the analysis: the experience of the authors can reduce this issue, but some complex thunderstorms can be classified in a different way depending on the point of view. In any case, the number of doubtful events was reduced compared with the total number. The second point is that only those cases totally in the range of volumetric information of the radar network were included (see, for instance, [23]). This consideration avoided having the wrong perspective of the selected thunderstorm. In the case of the SLJsts, the percentage of discarded elements was $15 \%$ (the total of valid thunderstorms was 675). However, for the MLJsts, only $37 \%$ of cases were used (605). We preferred reducing the total number of cases (that is, comparable with the SLJsts) to generate a large set of misclassified events. 

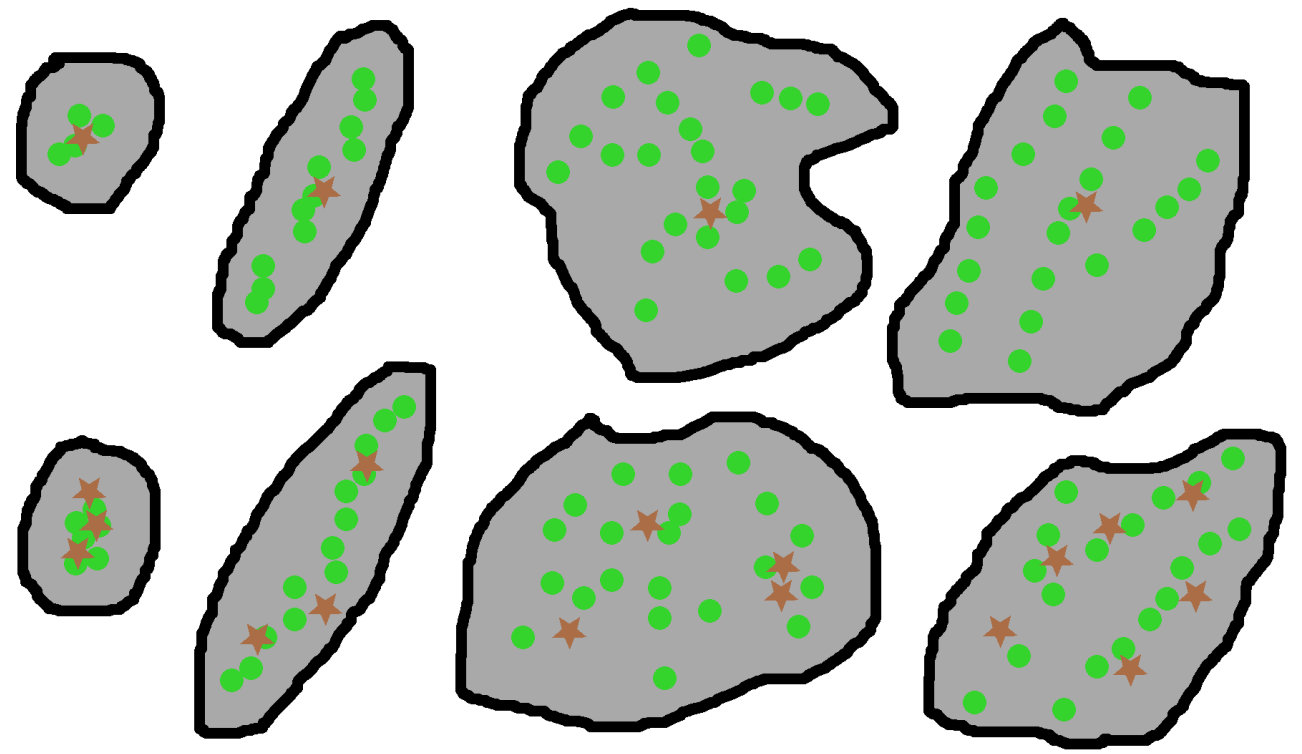

Figure 14. Scheme of the classification of the LJ-producing thunderstorms according to the number of jumps (brown stars): SLJsts (above) or MLJsts (below). The shadowed grey area indicates the limits of the thunderstorm based on the reflectivity footprint, while the green dots correspond to the cells identified using the algorithm of [21]. From left to right: isolated (a unique convective cell with a reduced path), lineal (a unique convective cell with a large trajectory), unorganised (multiple convective cells following unconnected paths), and organised (multiple cells with parallel or quasi-parallel trajectories, or the result of the splitting and merging processes).

Table 2 summarises the distribution of the cases for each type of thunderstorm (SLJst or MLJst), which, at the same time, were sub-classified depending on the maximum degree of the warnings ( 1 or 2 ). The key elements of the classification (see the caption of the table for the definition of the different categories) were as follows: First, organised thunderstorms are the most common except in the case of MLJst1. Second, for this last category, the unique convective cells types predominated, in particular those with a lineal trajectory. Third, the isolated category was the least common except for SLJst1. Lastly, for those categories with Level 2 jumps (SLJst2 and MLJst2), a clear predominance of the organised structures existed.

Table 2. Distribution of convective modes according to the number of jumps (single or multiple) and the level of the LJ (1 or 2$)$.

\begin{tabular}{lllll}
\hline & Isolated & Lineal & Unorganised & Organised \\
\hline SLJst1 & 104 & 50 & 186 & 241 \\
\hline SLJst2 & 9 & 10 & 25 & 50 \\
\hline MLJst1 & 64 & 88 & 34 & 36 \\
\hline MLJst2 & 41 & 107 & 106 & 129 \\
\hline
\end{tabular}

\section{Discussion}

The novelty of the research makes it complicated to find other works useful for comparison with the current results. In any case, some references showed equivalence with the analysis of MLJsts, mainly in the sense that they referred to severe phenomena and the convection that produced them. In the case of the time distributions of the thunderstorms, the comparative research works referred mainly to the region of study (Catalonia and the surroundings). References [24,25] showed the high degree of occurrence of severe weather in thunderstorms moving along an anomalous path (e.g., splitting, merging, or deviation from the normal flow). In this way, Reference [26] analysed convective 
thunderstorms with anomalous trajectories through weather radar data, finding that March to September presented the largest number of convective cases. This monthly distribution agrees with that observed in the current research. The same occurs with severe phenomena: Reference [4] presented a peak of activity between the months of May and September and, in the case of the hourly distribution, between 12 UTC and 20 UTC, also coincident with the thunderstorms producing LJs. Then, it is consequent that the analysis of hailstorms for the western part of Catalonia [21] also coincides in the monthly distribution. On the other hand, the comparison with mesoscale convective systems (MCSs) in Catalonia [27] presents notable differences, with a maxima of activity during the months of March, April, September, October, and November and for the hours of the day between 18 UTC and 22 UTC. This is because only a portion of the MCSs present an intense electrical activity, and then, the occurrence of LJs in those thunderstorms is less frequent.

Compared with other analyses for European regions ([9] or [16]), the time and monthly distributions follow similar regimes, with differences according to the local topographic conditions. To end this first comparison, the hourly distribution was compared with infrared satellite overshooting (OT), another severe weather indicator [28]. Reference [29] showed the high interaction between OT and LJs in severe thunderstorms. Then, the European analysis of [28] indicated also that the maxima of OT coincided with the period 12 UTC to 18 UTC in the case of Catalonia.

Moving to the radar parameters observed in thunderstorms producing LJs, the number of references for performing a direct comparison is larger than in the previous case. For instance, Reference [11] found that clusters producing LJs have a greater duration, which has a certain similitude with the fact that, having more than one jump, the organisation and the number of cells in the thunderstorm increase. Besides, References $[9,11,15,16]$ observed a larger intensity in different radar parameters in those thunderstorms that produced at least one LJ. Again, the present research followed the same line, but went a step further, indicating that it is not only a question of intensity if not also of the maintenance of these large values observed in the different radar parameters: MLJsts, and mainly in the case of Level 2, have durations of intensity much longer than the rest of the thunderstorms.

Finally, the analysis of the convective mode of the thunderstorms gives an explanation to the previous point (thunderstorms maintaining large values of radar parameters): the organisation of the convection in MLJsts is much larger than in other cases, with a predominance of structures with a long linear path for a unique convective cell, or multiple cells moving parallel or producing well-defined splitting and merging processes. Both cases can be associated with super-cellular convection, according to [30]. Besides, multiple cells moving parallel is the classic structure of MCSs or squall-lines with well-defined lines of cells ([31] or [27]). In both cases, supercells and MCSs, this refers to the convective structures with the highest degree level of organisation [32].

\section{Conclusions}

To sum up, most of the thunderstorms producing LJs are associated with the diurnal cycle of convection (occurring between 12 UTC and 18 UTC) and with the months with the peak of solar insolation (March to September). One important conclusion is that more than two thirds of these thunderstorms produce more than one jump (MLJsts). Besides, MLJsts have a larger probability of producing Level 2 jumps (60\% in front of the $15 \%$ that happens in SLJsts).

Regarding the relationship with radar parameters, the main points are:

- Thunderstorms with Level 2 LJs include more convective cells interacting;

- There are notable differences in the maximum values between SLJsts and MLJsts, with largest values in the second case;

- In any case, the main differences are observed when the analysis is focused on the duration of the more intense cores in the thunderstorm. 
Finally, the organisation of the convective cell(s) in the structure of the thunderstorm has a major role in its intensification, with long-linear paths or splitting-merging processes occurring during the life cycle.

These results can help to improve the operational forecasting tasks and, besides, to have better knowledge of this type of thunderstorm, which has a high relationship with extreme precipitation cases in many regions of the globe.

Author Contributions: Conceptualisation, T.R. and C.F.; methodology, T.R.; software, T.R.; validation, C.F.; formal analysis, T.R. and C.F.; investigation, T.R. and C.F.; data curation, T.R.; writing-original draft preparation, T.R.; writing-review and editing, C.F.; visualisation, T.R. and C.F. All authors have read and agreed to the published version of the manuscript.

Funding: This research received no external funding.

Institutional Review Board Statement: Not applicable.

Informed Consent Statement: Not applicable.

Data Availability Statement: Not applicable.

Acknowledgments: The authors want to thank to the colleagues of the Meteorological Service of Catalonia for the provided help and to the three anonymous reviewers for their interesting suggestions and comments.

Conflicts of Interest: The authors declare no conflict of interest.

\section{Abbreviations}

The following abbreviations are used in this manuscript:

CAPPI Constant altitude plan position indicator

CG Cloud-to-ground

CSI Critical success index

IC Intra-cloud

LJ Lightning jump

LJ1 LJ from multi-source lightning

LJ2 LJ from single-source lightning

LLS Lightning Location System

LF Low frequency

SMC Meteorological Service of Catalonia

TL Total lightning

VHF Very high frequency

VIL Vertical integrated liquid

SLJst Thunderstorms producing a single LJ

MLJst Thunderstorms producing multiple LJs

SLJst1 Thunderstorms producing a single LJ of Level 1

MLJst1 Thunderstorms producing multiple LJs of Level 1

SLJst2 Thunderstorms producing a single LJ of Level 2

MLJst2 Thunderstorms producing multiple LJs with at least one of Level 2

\section{References}

1. Farnell, C.; Rigo, T.; Pineda, N. Lightning jump as a nowcast predictor: Application to severe weather events in Catalonia. Atmos. Res. 2017, 183, 130-141. [CrossRef]

2. Gatlin, P.N.; Goodman, S.J. A total lightning trending algorithm to identify severe thunderstorms. J. Atmos. Ocean. Technol. 2010, 27, 3-22. [CrossRef]

3. Schultz, C.J.; Petersen, W.A.; Carey, L.D. Preliminary development and evaluation of lightning jump algorithms for the real-time detection of severe weather. J. Appl. Meteorol. Climatol. 2009, 48, 2543-2563. [CrossRef]

4. Farnell, C.; Rigo, T. The Lightning Jump, the 2018 “Picking up Hailstones" Campaign and a Climatological Analysis for Catalonia for the 2006-2018 Period. Tethys 2020, 17, 10-20. [CrossRef]

5. Farnell, C.; Rigo, T. The lightning jump algorithm for nowcasting convective rainfall in Catalonia. Atmosphere 2020, $11,397$. [CrossRef] 
6. Wu, F.; Cui, X.; Zhang, D.L. A lightning-based nowcast-warning approach for short-duration rainfall events: Development and testing over Beijing during the warm seasons of 2006-2007. Atmos. Res. 2018, 205, 2-17. [CrossRef]

7. Farnell, C.; Rigo, T.; Pineda, N. Exploring radar and lightning variables associated with the Lightning Jump. Can we predict the size of the hail? Atmos. Res. 2018, 202, 175-186. [CrossRef]

8. Schultz, C.J.; Petersen, W.A.; Carey, L.D. Lightning and severe weather: A comparison between total and cloud-to-ground lightning trends. Weather Forecast. 2011, 26, 744-755. [CrossRef]

9. Nisi, L.; Hering, A.; Germann, U.; Schroeer, K.; Barras, H.; Kunz, M.; Martius, O. Hailstorms in the Alpine region: Diurnal cycle, 4D-characteristics, and the nowcasting potential of lightning properties. Q. J. R. Meteorol. Soc. 2020, 146, 4170-4194. [CrossRef]

10. Yao, W.; Zhang, Y.; Meng, Q.; Wang, F.; Lu, W. A comparison of the characteristics of total and cloud-to-ground lightning activities in hailstorms. Acta Meteorol. Sin. 2013, 27, 282-293. [CrossRef]

11. Chronis, T.; Carey, L.D.; Schultz, C.J.; Schultz, E.V.; Calhoun, K.M.; Goodman, S.J. Exploring lightning jump characteristics Weather Forecast. 2015, 30, 23-37. [CrossRef]

12. Schultz, E.V.; Schultz, C.J.; Carey, L.D.; Cecil, D.J.; Bateman, M. Automated storm tracking and the lightning jump algorithm using GOES-R Geostationary Lightning Mapper (GLM) proxy data. J. Oper. Meteorol. 2016, 4, 92. [CrossRef] [PubMed]

13. Murphy, M.J.; Said, R.K. Comparisons of lightning rates and properties from the US National Lightning Detection Network (NLDN) and GLD360 with GOES-16 Geostationary Lightning Mapper and Advanced Baseline Imager data. J. Geophys. Res. Atmos. 2020, 125, e2019JD031172. [CrossRef]

14. Rudlosky, S.D.; Fuelberg, H.E. Documenting storm severity in the mid-Atlantic region using lightning and radar information. Mon. Weather Rev. 2013, 141, 3186-3202. [CrossRef]

15. Schultz, C.J.; Carey, L.D.; Schultz, E.V.; Blakeslee, R.J. Insight into the kinematic and microphysical processes that control lightning jumps. Weather Forecast. 2015, 30, 1591-1621. [CrossRef]

16. Wapler, K. The life-cycle of hailstorms: Lightning, radar reflectivity and rotation characteristics. Atmos. Res. 2017, 193, 60-72. [CrossRef]

17. Xu, S.; Zheng, D.; Wang, Y.; Hu, P. Characteristics of the two active stages of lightning activity in two hailstorms. J. Meteorol. Res. 2016, 30, 265-281. [CrossRef]

18. Nag, A.; Rakov, V.A. Some inferences on the role of lower positive charge region in facilitating different types of lightning. Geophys. Res. Lett. 2009, 36, L05815. [CrossRef]

19. Nag, A.; Rakov, V.A. Pulse trains that are characteristic of preliminary breakdown in cloud-to-ground lightning but are not followed by return stroke pulses. J. Geophys. Res. Atmos. 2008, 113, D01102. [CrossRef]

20. Dwyer, J.R.; Uman, M.A. The physics of lightning. Phys. Rep. 2014, 534, 147-241. [CrossRef]

21. Rigo, T.; Llasat, M.C. Forecasting hailfall using parameters for convective cells identified by radar. Atmos. Res. 2016, 169, 366-376. [CrossRef]

22. Wilks, D.S. Statistical Methods in the Atmospheric Sciences; Academic Press: Cambridge, MA, USA, 2011; Volume 100.

23. Rigo, T.; Llasat, M.C.; Esbrí, L. The Results of Applying Different Methodologies to 10 Years of Quantitative Precipitation Estimation in Catalonia Using Weather Radar. Geomatics 2021, 1, 20. [CrossRef]

24. del Moral, A.; Rigo, T.; Llasat, M.C. A radar-based centroid tracking algorithm for severe weather surveillance: Identifying split/merge processes in convective systems. Atmos. Res. 2018, 213, 110-120. [CrossRef]

25. Cotton, W.R.; Bryan, G.H.; Van den Heever, S.C. Storm and Cloud Dynamics; Academic Press: Cambridge, MA, USA, 2010.

26. del Moral, A.; del Carmen Llasat, M.; Rigo, T. Identification of anomalous motion of thunderstorms using daily rainfall fields. Atmos. Res. 2017, 185, 92-100. [CrossRef]

27. Rigo, T.; Berenguer, M.; del Carmen Llasat, M. An improved analysis of mesoscale convective systems in the western Mediterranean using weather radar. Atmos. Res. 2019, 227, 147-156. [CrossRef]

28. Bedka, K.M. Overshooting cloud top detections using MSG SEVIRI Infrared brightness temperatures and their relationship to severe weather over Europe. Atmos. Res. 2011, 99, 175-189. [CrossRef]

29. Jurković, P.M.; Mahović, N.S.; Počakal, D. Lightning, overshooting top and hail characteristics for strong convective storms in Central Europe. Atmos. Res. 2015, 161, 153-168. [CrossRef]

30. Zeitler, J.W.; Bunkers, M.J. Operational forecasting of supercell motion: Review and case studies using multiple datasets. Natl. Weather Dig. 2005, 29, 81-97.

31. Houze, R.A., Jr. Mesoscale convective systems. Rev. Geophys. 2004, 42, RG4003. [CrossRef]

32. Yu, X.; Zheng, Y. Advances in severe convection research and operation in China. J. Meteorol. Res. 2020, 34, 189-217. [CrossRef] 